\title{
Breton-Cortázar: vida de los objetos
}

\author{
Andrés Mora**
}

\begin{abstract}
RESUMEN
Recibido: 20 de febrero de 2015

Este trabajo estudia la vida de los objetos a partir de las correspon-

Evaluado: 2 de marzo de 2015 dencias entre Breton y Cortázar. Por un lado, reflexiona sobre el Aceptado: 22 de abril de 2015 porqué de restituir al objeto su sentido en pro del descubrimiento de su ser poético; por el otro, da luz al diálogo fundamental que existe entre ambos para una mejor comprensión del mundo de Oliveira en Rayuela, como de la actitud poética que eligieron a la hora de transfigurar la realidad en nombre de la vida.
\end{abstract}

Palabras clave: Breton, Cortázar, objeto surrealista, Rayuela. 


\title{
Breton-Cortázar: objects' life
}

\begin{abstract}
This work studies the life of objects based on the similarities between Breton and Cortázar. On the one hand, it reflects on the importance of restoring to the object its meaning in order to discover and understand its poetic existence; on the other hand, it illustrates the important dialogue that exists between both of them for a better comprehension of Oliveira's world in Rayuela, as well as their poetic attitude when changing reality as a means to change life.
\end{abstract} Received: February 20, 2015 Evaluated: March 2, 2015 Accepted: April 22, 2015

Keywords : Breton, Cortázar, surrealist object, Rayuela. 


\section{Breton-Cortazar: vida dos objetos}

\section{Resumo}

Recebido: 20 de fevereiro de 2015

Avaliado: 2 de março de 2015 Aceito: 22 de abril de 2015
Este trabalho estuda a vida dos objetos a partir das correspondências entre Breton e Cortazar. Por um lado, reflete sobre o porquê de restituir ao objeto seu sentido a favor do descobrimento de seu ser poético; por outro lado, clareia o diálogo fundamental existente entre ambos para uma melhor compreensão do mundo de Oliveira em Rayuela, como da atitude poética que elegeram no momento de transfigurar a realidade em nome da vida.

Palavras-chave: Breton, Cortázar, objeto surrealista, Rayuela. 
En el primer capítulo de Rayuela, la errancia de Horacio Oliveira por la Rue de Seine termina en el Pont des Arts. Sube los peldaños; observa el pretil del puente, las aguas del río. Hace tiempo está cansado: cansado de privar las cosas de su rostro, de mirarlas hasta no verlas. Un cansancio, medita Oliveira, como la tristeza de "un paraguas mojado que se cierra" (Cortázar, 2003, p. 120). Entonces evoca aquel paraguas viejo, algo roto que la Maga encontró en la Place de la Concorde y que luego en una tarde de lluvia, con la tela desgarrada y el armazón arruinado, fue finalmente enterrado. Porque un paraguas no podía ser solo una cosa

[...] debía morir dignamente en un parque, no podía entrar en el ciclo innoble del tacho de la basura [...] Entonces yo lo arrollé lo mejor que pude [...] Y quedó entre el pasto, mínimo y negro, como un insecto pisoteado. $\mathrm{Y}$ no se movía, ninguno de sus resortes se estiraba como antes. Terminado. Se acabó. Oh Maga, y no estábamos contentos (p. 121).

Errar es buscar algo. Errar por París como Cortázar y Breton era crear un mundo con la inquietud del niño que imagina los artefactos que lo miran desde el escaparate de la juguetería. Esos objetos ocultos en los mercados de pulgas que adquiría Breton en su errar, porque prometían un sentido especial como el juguete lo entraña para el niño. Esa tarde para Oliveira el encuentro fue con un paraguas. Una noche, al deambular por París, será un retal de trapo rojo arrojado en un rincón de la calle (Cortázar, 2003, p. 128); o quizá tras la medianoche, al final de otro itinerario, al ingresar en el pasillo del departamento hallarse de súbito ante un zapato clavado en una puerta unido a un pedazo de acordeón verde (p. 289). En ese momento para Breton y Cortázar había una señal: las cosas hablaban.

Al imaginar el zapato clavado en la puerta aparece un sentimiento de desconcierto. Por un lado, su posición espacial insólita; por el otro, su situación ajena a su natural usanza. La conducta del objeto es confusa. Es en el momento de extrañeza ante el mismo cuando este da apertura a la sensación de un develamiento hasta ahora subestimado y desconocido por nosotros. Para Breton y Cortázar, como lo ve Oliveira, la aproximación de este contacto es la proximidad de un desocultamiento: su existencia éntica se descubre. Es un descubrimiento en dos sentidos: el descubrirse de lo aparencial fenomenológico que da paso al descubrimiento de una nueva mostración. Por ello dice Breton (1988), en el Manifeste du surréalisme, y lo citará Cortázar en Cristal con una rosa dentro: “'La rosa es una rosa. La rosa no es una rosa. Y sin embargo, la rosa es una rosa' pero que se me permita [...] arrastrar a 'la rosa' en un movimiento provechoso de contradicciones" (p. 794). Podemos decir que en el instante del descubrirse en la hendidura del claro el objeto se ha desenmascarado. El advenimiento de esta experiencia era el que presagiaba Breton ante los objetos que reunió a lo largo de su vida y cuidó en el 42 de la Rue Fontaine. Este advenir lo presiente Oliveira al hallar pelusas dentro del paquete de cigarrillos (Cortázar, 2003, p. 127). Entonces la esencia de las cosas es otra (figura 1). Para recordar a Dalí tendido en un sofá mientras sostiene un paraguas abierto que hace las veces de protector onírico o para-pesadillas; el taxi pluvieux decorado con plantas brotando de las ventanas y 
Figura1. Phonographe de Domínguez: Jamais, Denise Bellon (1938).

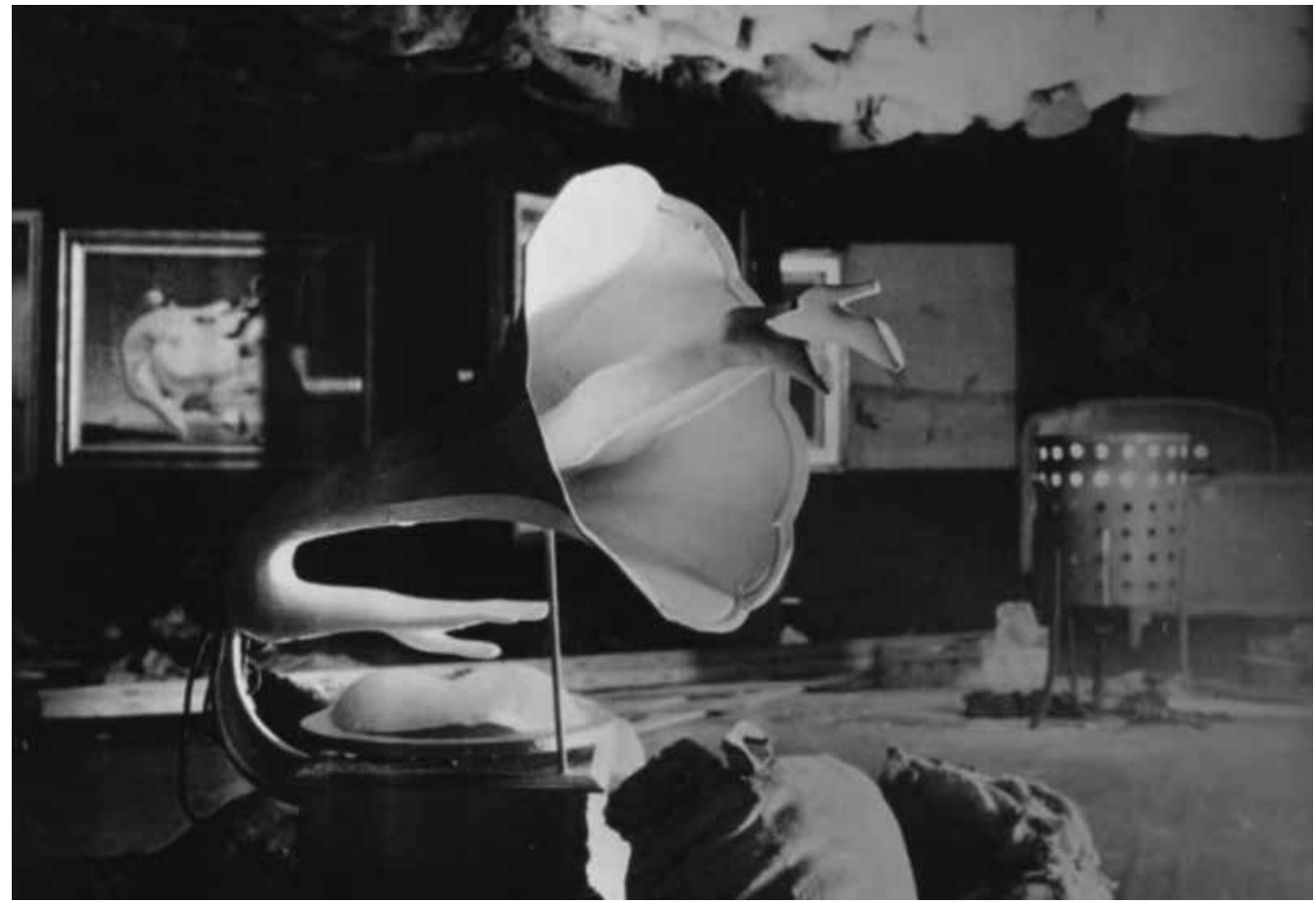

Fuente: http://binocheetgiquello.com/

maniquíes de mujer con el rostro cubierto, instalado en la entrada inaugural de la Exposition internationale du surréalisme en la Galerie Beaux-arts, el 17 de enero de 1938 (figura 2).

El reino del juguete y el niño es siempre sorpresa, por ello hay en Cortázar y Breton la persistencia en preservar sus sendas, más aún cuando la inercia de la vida profana las sustrae. Todo objeto guarda una incógnita si se lo sabe mirar (figura 4), si hay una apreciación más allá de su identidad imperante, sentido venal y uso estético-decorativo. Esto significa el alejamiento de su apariencia (Méndez, 2010). Entonces es posible captar su comportamiento y sospechar su presencia. En Breton se trata de un diálogo continuo con ellos, a veces táctil,
Figura 2. Le taxi pluvieux de Salvador Dalí. Denise Bellon (1938).

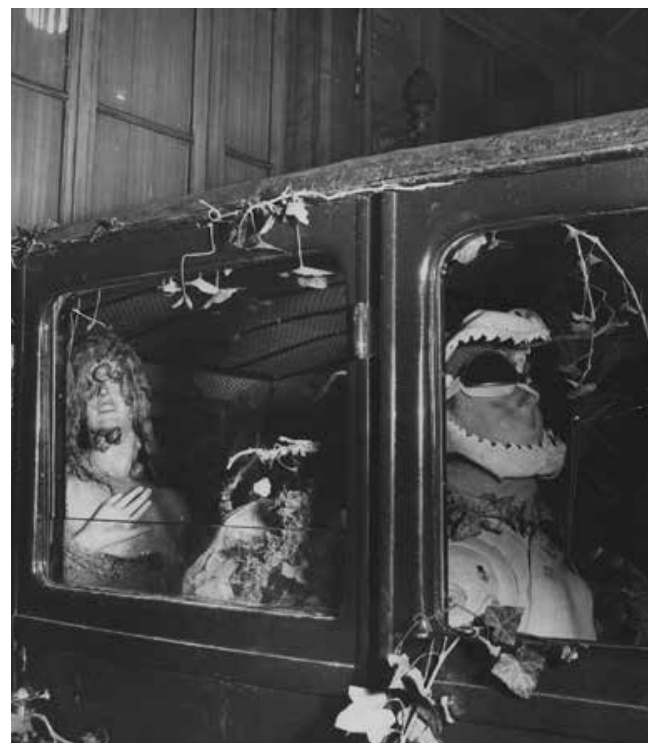

Fuente: http://www.andrebreton.fr 
a veces transponiéndolos como en Nadja y L'amour fou. Como fuere, su contacto partía del juego. Por ello Cortázar (2003) cuenta de ese hombre que pasó años contemplando un tornillo en el suelo; en las noches lo ponía debajo del colchón; todos reían. Pero un día murió y el tornillo desapareció al acudir los vecinos. Nadie entendía; el error estaba en querer entender: "aceptar que ese objeto era un tornillo por el hecho de que tenía la forma de un tornillo" (p. 545). Este hombre podía ser juzgado de idiota, escribe Cortázar, pero había adivinado un mundo. Los demás seguían viendo un tornillo.

La postura determinista anula el tornillo: a todas las cosas. Esta actitud es clara en el episodio de los frijoles saltarines en el que se molestó Breton. El 26 de diciembre de 1934, Lacan y Caillois lo visitaban. "Sus amigos estaban divertidos con la infantil fascinación de Breton por lo que parecía ser una especie de milagro, y con su renuencia a abrir los fríjoles para encontrar la causa de la aparente magia" (Balakian, 1971, p. 376). Breton se opuso cuando Caillois quiso abrirlos. Lo que contaba para él era la actitud ante el misterio, no su disección. La represión del sentido de la magia en la vida cotidiana solo denunciaba a Breton y Cortázar el grado de pobreza mental en el que transcurría la vida de la mayoría ${ }^{1}$. ¿Por qué se ha despojado de magia al frijol?

Viven las cosas si retornan a su inocencia primigenia: si se las mira y toca por primera vez. Esta era la clave de Breton. Por ello dice en el Manifeste "la consciencia poética de los

La discusión sobre lo fantástico acaba al romper Caillois con Breton (Bradu, 2012). Esta objeción la hace Caillois a Cortázar: "'lo explicable' -responde él-siempre me ha parecido un fracaso" (2006, p. 614). objetos, que no he podido adquirir sino con su contacto espiritual mil veces repetido" (1988, p. 335). Esto es lo que Oliveira busca al restituirles su enigma, su rostro. A lo largo de su búsqueda, un día Oliveira sintió que necesitaba fijar la mirada en la silueta que trazaba el objeto con su sombra. Contempló lo que solo acostumbraba ver; captó la aureola que lo envolvía. Y las sombras de los objetos, como expresa Luis Puelles (2005), "se hicieron mirar" (p. 13). Los objetos estaban presentes, se tornaban inquietantes, reclamaban su atención. La generación de Breton lo sintió: a partir de esta reclamación Breton y sus compañeros dispensaron el cuidado debido a la mágica "crisis fundamental del objeto" (1999, p. 827), como resumió junto a Éluard en el Dictionnaire abrégé du surréalisme, el catálogo para la exposición de 1938. Para volver a Oliveira, quizá sea la aventura de la noche del terrón de azúcar aquella en la que mejor podamos notar el movimiento del objeto y a la vez reparar en su atención ante la crisis del mismo.

[Estábamos] en el restaurante de la rue Scribe $[. .$.$] y a mí se me cayó un terrón$ de azúcar que fue a parar abajo de una mesa bastante lejos de la nuestra. Lo primero que me llamó la atención fue la forma en que el terrón se había alejado, porque en general los terrones de azúcar se plantan apenas tocan el suelo [...] Pero éste se conducía como si fuera una bola de naftalina... me tiré al suelo y empecé a buscar el terrón de azúcar entre los zapatos de la gente que estaba llena de curiosidad creyendo (y con razón) que se trataba de algo importante [...] Para peor el piso tenía alfombra, y aunque estaba asquerosa de usada el terrón se había escondido entre los 
pelos y no podía encontrarlo. El mozo se tiró del otro lado de la mesa, y ya éramos dos cuadrúpedos moviéndonos entre los zapatos-gallina que allá arriba empezaban a cacarear como locas. El mozo seguía convencido de la Parker o el luis de oro [...] y empecé a agarrar los zapatos de las mujeres [...] hasta encontrar el azúcar escondido detrás de una pata segundo imperio [...] esa clase de episodios todos los días (Cortázar, 2003, pp. 129-131).

En el instante del claro hacia la realidad del objeto su rostro ha emergido como aparición que irrumpe en el espacio real al despojarse de su semblante: el objeto se está manifestando. Oliveira ha desentrañado la virtud mágica del terrón de azúcar. Ahora el carácter enigmático que solo veía Adorno (1986) encerraba el objeto de arte junto con "la solución de su insoluble enigma" (p. 170), es también virtud del terrón de azúcar. En El origen de la obra de arte escribía Heidegger (1995): "[sabemos] qué es el utensilio. De este modo también ha salido a luz lo que obra dentro de la obra: la apertura de lo ente en su ser" (p. 31). A la luz del surrealismo el objeto no es un utensilio: el objeto ha dado apertura al enigma mágico e insoluble de su ser.

Volviendo a Breton y Cortázar, retomemos el terrón. Precisamente si se ha percatado un enigma por descifrar en la instancia en que el objeto se muestra, la emisión de este mensaje no existiría si no lo aguardara Oliveira. Aquí comprendemos, parcialmente, lo que ambos perseguían en su deambular y aquello demás que atribuían a los objetos: ellos insinuaban un mensaje esencial que atañía a sus vidas. El desenmascaramiento de estos otorgaba una señal que seguir, un signo que penetrar. El señuelo del objeto era el desciframiento de una clave de índole privado. Cuanto más esotérico, más fuerte su poder augural. Por ello la atracción de Breton hacia aquéllos ajenos al juicio de valor de Occidente: los fetiches de Oceanía, las máscaras africanas y precolombinas, las muñecas Hopi de los piel roja eran algunos de los objetos primitivos en los que veía un poder magnético, a tal punto que había desarrollado un instinto perspicaz a la hora de contemplarlos y advertir cosas que otros no podían captar en ellos, recuerda Lévi-Strauss (Polizzotti, 2009). Esta fascinación la compartía Cortázar. Conservaba en su casa algunos objets trouvés que estimaba. Por ejemplo, una jaula pequeña con una raíz de mandrágora. La llamaba $E l$ obispo de Evreux ${ }^{2}$.

Lo esotérico otorga encanto a las cosas. Tal vez sea aquí la estatua de Giacometti L'objet invisible la que mejor trasparezca el arcano que poseían estas ante todo para Breton (figura 3). La figura representa a un ser erguido cuyas manos presentan la disposición de estar sosteniendo algo. Las manos se suspenden en el vacío manteniendo el espacio respectivo que entre ellas ocupa el objeto. Pero este debe ser imaginado porque no es posible ver lo que puedan retener. De la estatua, presentada en L'amour fou, dice Breton (1999): "la desaparición del objeto invisible pero presente" (p. 698). A partir de aquí podemos decir que el reino del objeto está tras el umbral de la imaginación. Y he aquí a la vez el porqué de dar vida a objetos inexistentes. Lo que cautivaba a Breton de la estatua era el hecho de no poder ver el objeto pero saberlo existente. En efecto,

2 Lo presenta Cortázar en la sobretapa de Último round. 
El obispo de Evreux de Cortázar es un objeto imaginado. Como vio Breton en 1924 en Introduction au discours sur le peu de réalité, existía un portal invisible en el que tocar: "Para responder a este deseo de verificación perpetua, recientemente propuse fabricar, en la medida de lo posible, algunos de esos objetos a los que uno se acerca sólo en el sueño y que no parecen defendibles ni bajo el concepto de la utilidad ni bajo el del entretenimiento" (1974, p. 20), objetos como El obispo de Evreux que son la expresión de El nacimiento del mobiliario paranoico (1937), para evocar la obra de Dalí. Estos objetos ensoñados son el nacimiento de l'objet surréaliste: fueron trasladados de la invisibilidad de la esfera onírica e imaginaria al plano concreto. Como Breton en la Rue de la Fontaine, Cortázar se había rodeado de ellos. Los más valiosos quizá le eran los que había fabricado su fantasía. Evelyn Picon (1990), quien lo visitó en su casa de Saignon en 1973, recuerda:

En la pared colgaba una creación suya. Era una especie de caja cubierta por una telaraña de hilos [...] Dentro de la caja, a un lado, descansaba un cartón para huevos abierto para ostentar unos compartimientos en que Julio había colocado caracoles y una vela negra. Otros objetos surrealistas [...] una pequeña caja de casillas llena de espejos rotos, caracoles y piedrecitas pintadas. Ésta tenía una puerta roja que se cerraba con manija hecha de una brújula. $\mathrm{Al}$ subir la estrecha escalera a la alcoba, se veía una pequeña escultura "a la manera Henry Moore", y en los estantes de la sala, peines de colores en forma de sirenas: "objetos encontrados" de Julio (p. 13).
Figura 3. Giacometti, L'objet Invisible. Man Ray (1934).

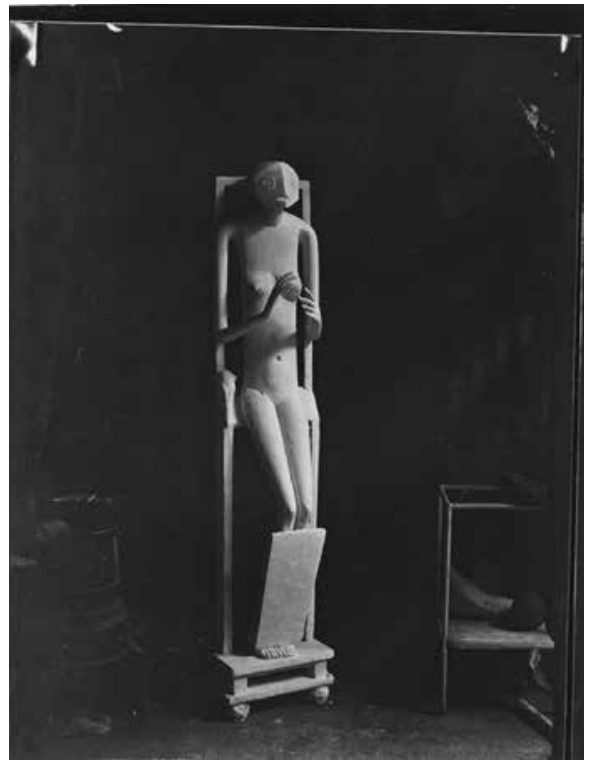

Fuente: http://www.centrepompidou.fr

Figura 4. La guenon et son petit. Pablo Picasso (1951). Cerámica, metal y escayola. La cabeza de la mona son dos coches de juguete contrapuestos, el espacio entre ellos forma la boca; la rejilla del radiador los pelos del hocico, dos asaz de tazas son las orejas, una jarra cerámica puesta bajo la cabeza forma el torso (Carsten y Ingo, 1992).

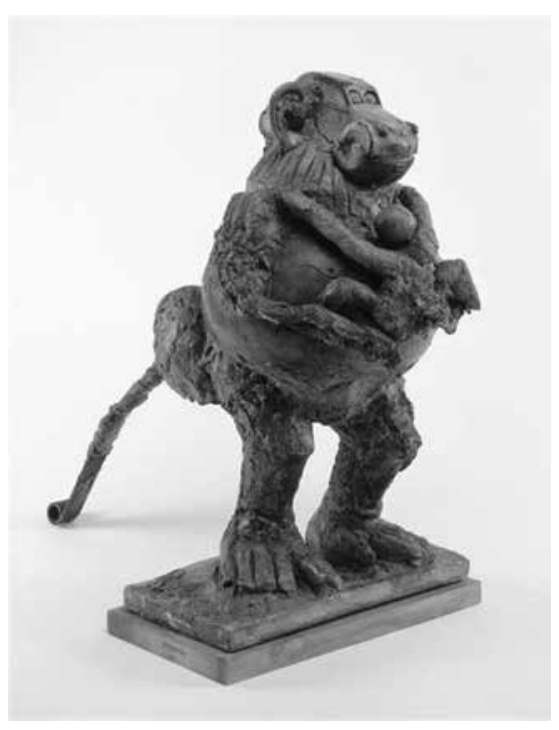

Fuente: http://www.museepicassoparis.fr 
La insinuación del principio de verificación formulado por Breton se cumplió hasta hacerse vigente. Como señaló Dalí (1977) en el número 1 de Minotaure aquello coincidió con la invención capital de los objets oniriques: aquellos "objetos delirantes destinados a ser puestos en circulación [...] a intervenir, a entrar en la vida corrientemente, cotidianamente en colisión con los otros, a la plena luz de la realidad" (p. 37). Ahora los objetos surrealistas se hallaban en fase embrionaria. $\mathrm{Su}$ análisis, apuntaba Dalí en Le surréalisme au servicie de la révolution, "nos hace entrever toda la violenta fantasía de su próxima vida prenatal" (1977, p. 169). Era un presagio para Breton y Cortázar que el halo que envuelve la vida del objeto es el de una atmósfera de ensueño. Si para Dalí había cierta aureola onírico-paranoica en las cortezas de pan, Oliveira ve en el pan su movimiento. La percepción de su repentina desemejanza lo desconcierta. El pan ha hablado: "esto sucedía en la cocina de la rue de la Tombe Issoire [...] Tenía hambre y agarré el pan para cortarme una tajada. Entonces oí que el pan lloraba" (Cortázar, 2003, p. 625). Sufría una mutación, desplegaba un abanico de visiones. Al estar sumergido bajo esta aureola su visión se ha trastornado en una entrevisión disímil de sí misma, a veces en un haz de entrevisiones ${ }^{3}$. Es el desocultamiento: asistimos al despliegue de sus imágenes poéticas.

En L'amour fou, Breton narra su experiencia al presenciar las simultáneas metamorfosis de un objeto curioso adquirido junto a Giacommeti en el mercado de pulgas a los

3 El método paranoico-crítico de Dalí - como la irrupción de imágenes en las figuras de Cortázar- extrae de la visión del objeto un despliegue sucesivo de otros derivados luego asociados y yuxtapuestos: del pan Dalí ha extraído un ruiseñor, un cuadro de Vermeer y los cuernos de un rinoceronte (Dalí, 1977). alrededores de Saint-Ouen. Por aquellos días de 1937 su amigo trabajaba en L'objet invisible, la estatua referida. Ese día Giacommeti adquirió una máscara cuya procedencia le inquietaba. Breton consideró que dicha inquietud latente en la máscara anunciaba un esclarecimiento para el artista respecto a la culminación de su escultura (quizá una alusión a la posible aparición de L'objet invisible). El objeto de Breton era el siguiente: una cuchara en cuyo extremo del mango se desprendía una pequeña bota que la levantaba a la altura que exigía su concavidad (figura 5). Como Oliveira ante el pan, la cuchara-zapato manifiesta una crisis de transformaciones; parece poder desplazarse por sus propios medios. La cuchara-zapato (relacionada por Breton con una de aquellas que manipuló Cenicienta antes de calzar su zapatilla) termina iluminando su enigma, además de otorgar a Breton una solución simbólica a una dificultad particular. Este objeto lo preservó toda su vida. Así, vemos cómo el objet trouvé que Breton espiaba en los mercados de pulgas anunciaba ya el advenimiento del l'objet Onirique, ese objeto que se reclamaba más allá de su existir virtual: ahora l'objet Onirique era real. En 1935 escribía Dalí en La conquista de lo irracional:

Las piedras preciosas que desaparecen al despertar y que en el sueño habíamos "conservado y dispuesto" con astucia, como testimonio de la existencia de la "deseada tierra de los tesoros" a la que se tenía acceso, conservan en el delirio paranoico, y tras su extinción bajo la mirada estúpida de todos, el peso exacto que corresponde a su volumen y la concreción delirante de sus contornos luminosos más físicos. Están “en la realidad" (1977, p. 38). 
Figura 5. De la hauteur d'un petit soulier faisant corps avec elle. Man Ray (1937). Usada por Breton para ilustrar L'amour fou.

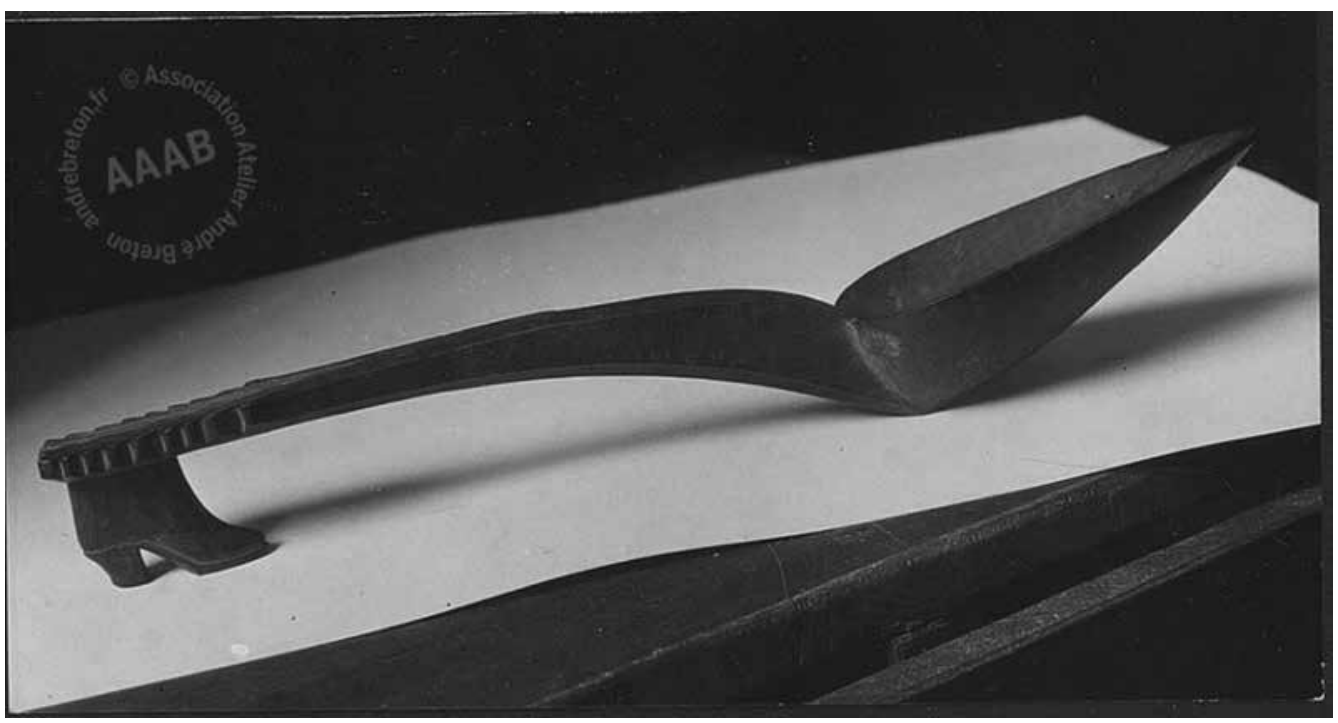

Fuente: http://www.andrebreton.fr

Al materializar el objeto onírico se impuso su existencia. El objeto era reivindicado como imaginaban Oliveira y la Maga ante el paraguas. En el segundo y tercer decenio del siglo $\mathrm{XX}$, el objeto anunció su renacimiento. Breton identificaba el punto de partida de este renacer en los ready-made de Marcel Duchamp ${ }^{4}$ en 1913 y los objetos enigmáticos assemblages de Man Ray (Lottman, 2003). En el momento que el orinal de porcelana (Fountain, 1917) y la plancha de vapor con tachuelas (The gift, 1921) fueron retirados de su realidad espacial perdieron su sentido.

4 En 1918 Duchamp viajó a Buenos Aires. Este viaje lo aclara Cortázar al hallar una entrevista al artista: en su cuarto Duchamp colgó trozos de caucho del techo y ató de sus extremos cordones extendidos por aquél. "'Por lo tanto —-dice Duchamp — cuando se entraba en la pieza no se podía circular pues los cordeles lo impedían"' (Cortázar, 2010, p. 188). Cuarenta años luego, expresa Cortázar, Oliveira enlazaba con esta concurrencia en su cuarto de asilo.
El llamado del objeto se escuchó desde su aislamiento, silencio e inmovilidad. Tras Dadá, a través del surrealismo, durante una búsqueda de tres décadas, la emancipación del objeto se manifestó en una prodigiosa exposición de creaciones que cobraban vida. Un momento en la vida de este sin precedentes en la historia del arte.

En los años cincuenta, en el París de Rayuela, Oliveira ha conservado el mensaje: recorre las calles, a veces topa con la Maga, a veces con algún objeto: otorga a su hallazgo el contenido de una respuesta. También a veces ella no tiene dinero "y si no [...] elegía una hoja de plátano en el parque" (Cortázar, 2003, p. 132). Ambos, Oliveira y Lucía, han ido más allá del objet trouvé: "por ese entonces yo juntaba alambres y cajones vacíos en las calles de la madrugada y fabricaba móviles, perfiles que giraban sobre las chimeneas, 
maquinas inútiles que la maga me ayudaba a pintar" (p. 132). Construcciones de Oliveira cuya manufactura emerge de una pulsión. Como recordaría Breton en Situation surréaliste de l'objet, tal como fue definido por Dalí (1977), estas creaciones "se prestan a un mínimo de funcionamiento mecánico y se basan en los fantasmas y representaciones susceptibles de ser provocados mediante la realización de actos inconscientes" (p. 168). Dalí los llamó objetos de funcionamiento simbólico. Valga referir su carácter sexual. La caja de telaraña de hilos que vio Picon (1990) en casa de Cortázar estaba protegida con un plástico que cubría el dibujo de un falo como el que asoció Breton ante la modificación figurativa de la cuchara en L'amour fou: "zapatilla=cuchara=pene $=$ molde perfecto de ese pene" (Breton, 1999, p. 707). Los móviles inútiles que inventa Oliveira fueron uno de los pasos fundamentales en nombre del objeto fruto de una voluntad de imaginación desbordante: el objet surréaliste. Con la
Figura 6. Boule suspendue. Alberto Giacometti (1930) (versión de 1965).

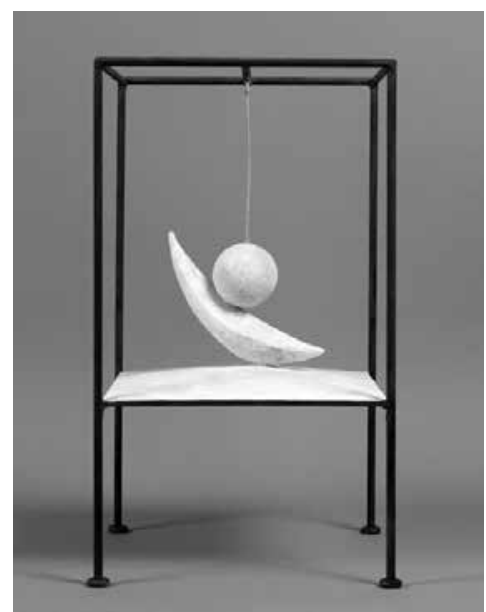

Fuente: http://www.fondation-giacometti.fr

aparición de los objetos de funcionamiento simbólico su vida se ensanchó. Su misterio fue más extraordinario. De la forma como el objet trouvé invocó el objet onirique y este les objets à fonctionnement symbolique (figura 7) de 1930 (inspirados en la expectación que

Figura 7. Objet à fonctionnement symbolique. André Breton (1931).

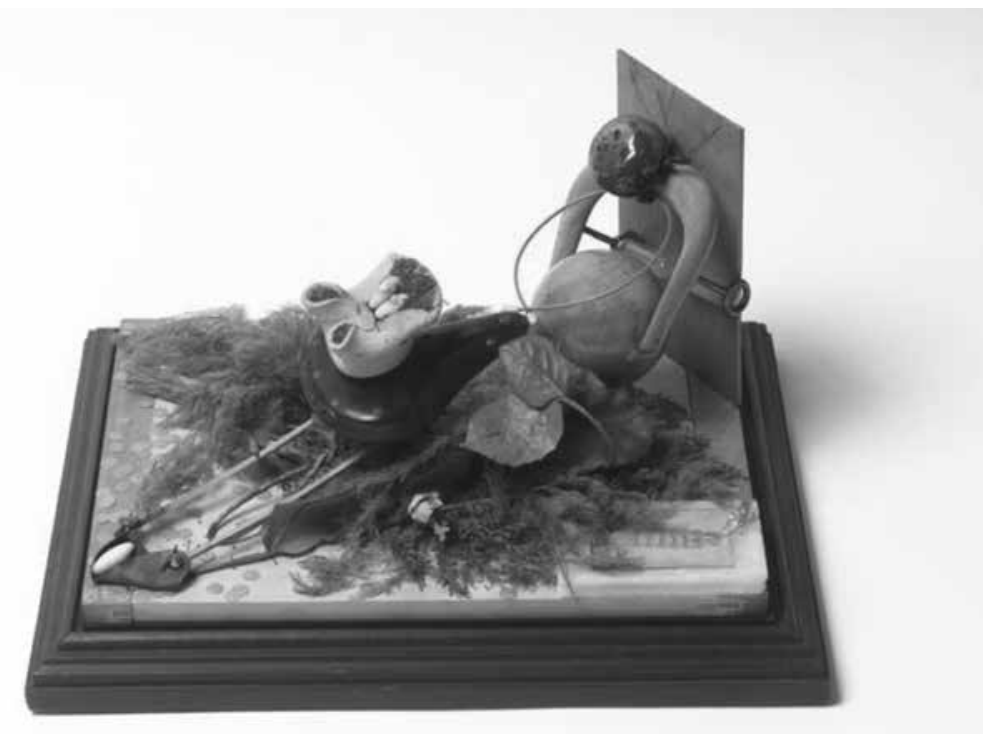

Fuente: http://www.centrepompidou.fr 
Figura 8. Vue de l'Exposition du surréalisme à la galerie Pierre Colle. Man Ray (1933). (Entre los objetos, être-objet anamorphique de Dalí). Galerie Pierre Colle.

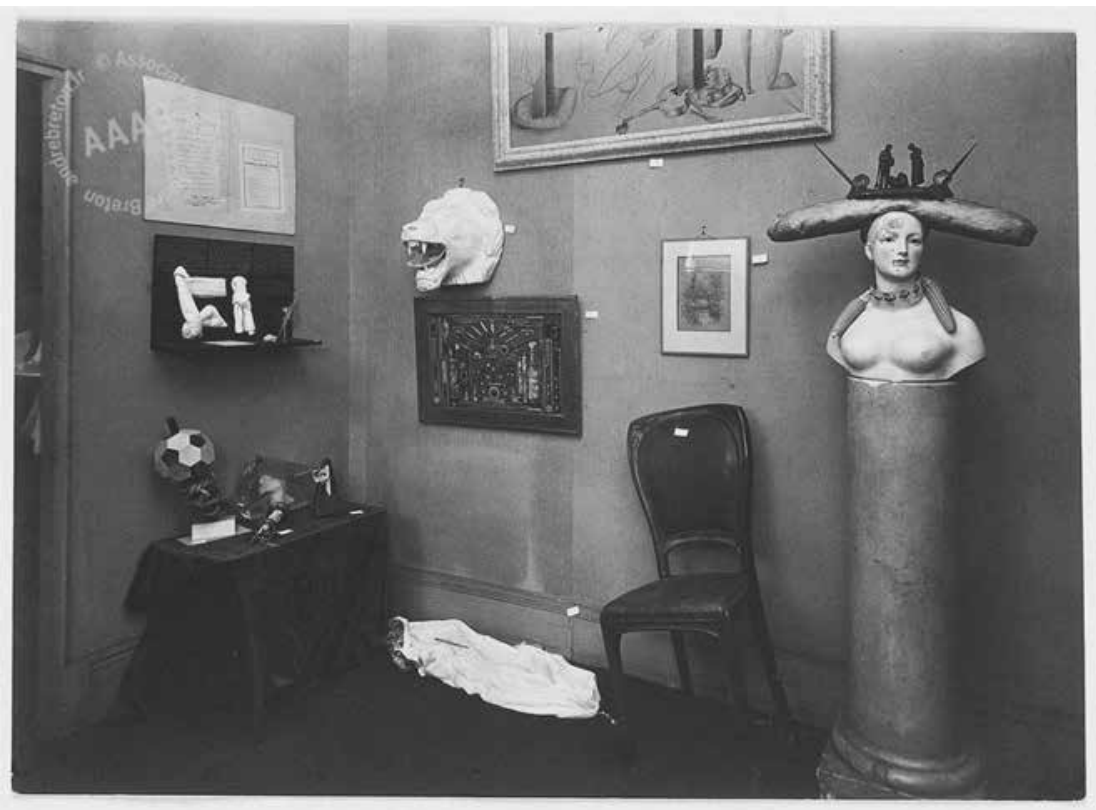

Fuente: http://www.andrebreton.fr

Figura 9. Pierres. Objets naturelles en Lesina. Raoul Ubac (1935).

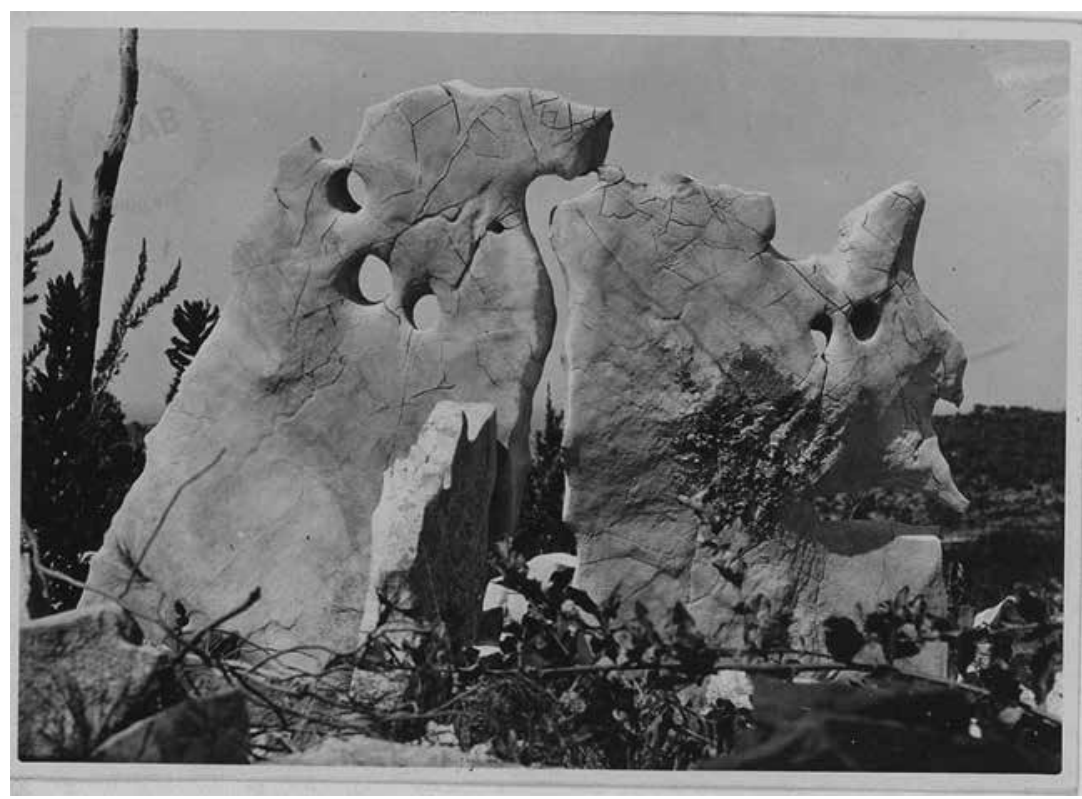

Fuente: http:// www.andrebreton.fr 
despertó la Boule suspendue de Giacometti) (figura 6) salieron a la luz, como cometas alucinados, el objet fantôme, el objet mobile et muet, el être-objet, el objet mathématique (hallado por Ernst y fotografiado por Ray en el Instituto Raymond Poincaré) y una capacidad de atención penetrante que expuso a la luz del día objets naturelles de una belleza pasmódica (figura 9). Algunos de ellos, hoy desaparecidos, estuvieron presentes en la Exposition internationale de 1938. Se pueden apreciar en el Dictionnaire de Éluard y Breton.

Fue el decenio de los treinta el mayor encumbramiento del objeto. Su volumen, sus formas se hicieron psíquicos y subversivos. Los estudios de Freud, su interpretación poética por Breton, permitieron encausarlos en una corriente erótica al proveerlos de atributos libidinosos (alrededor de 1930 nacen las muñecas de Hans Bellmer ${ }^{5}$. Tras su primera presentación en1933 en la Galerie Pierre Cole, pasando por su celebración en la Exposition internationale de l'objet en la Galerie de Charles Ratton en 1936, el objeto se convirtió en el anfitrión por excelencia de las exposiciones surrealistas. En el Dictionnaire abrégé las patas de un sillón de Seligmann se mudaban en piernas de mujer (Breton, 1999, p. 850), el respaldar de una silla de Paalen sugería un ser erguido (p. 797). Otros eran más turbadores: "alquilar a una viejecita limpia en el más alto grado de decrepitud, y exponerla, vestida de torero, colocándole encima de la cabeza, previamente afeitada, una tortilla a la francesa que temblará debido al continuo meneo de la cabeza de la viejecita. También se puede colocar una moneda de veinte francos encima de la tortilla" (Dalí, 1977, p. 70). Se trataba de un être-objet anamorphique

5 Ver la muñeca descuartizada fotografiada por Cortázar en Último round (planta baja). (figura 8). Hoy se puede apreciar una réplica en el Museo del Banco de la República.

Un être-objet era un objeto animado. En este sentido, pudo haber sido creado inconscientemente por la necesidad de mostrar el ser de las cosas. En la Exposition de 1938, Miro, Ray, Arp, Masson, Dalí, Duchamp, entre otros, instalaron en los corredores de la galería sus maniquíes (figura 11). Aquellos maniquíes con ojos humanos y formas mecánico-orgánicas en las pinturas de Chirico hicieron su arribo real (Aktypi, 2014). Como Pigmalión ante su estatua de marfil, existía el presagio de haber algo más en la naturaleza de lo inanimado. Y un día la estatua vivió; Pigmalión convivió con ella. Maravilloso era para los surrealistas ver cómo un arqueólogo se enamoraba de una figura femenina pedestre en un bajo relieve

Figura 10. Figura. Reinhoud D'Haese. 38 de ellas empleadas por Cortázar en Diálogo de las formas.

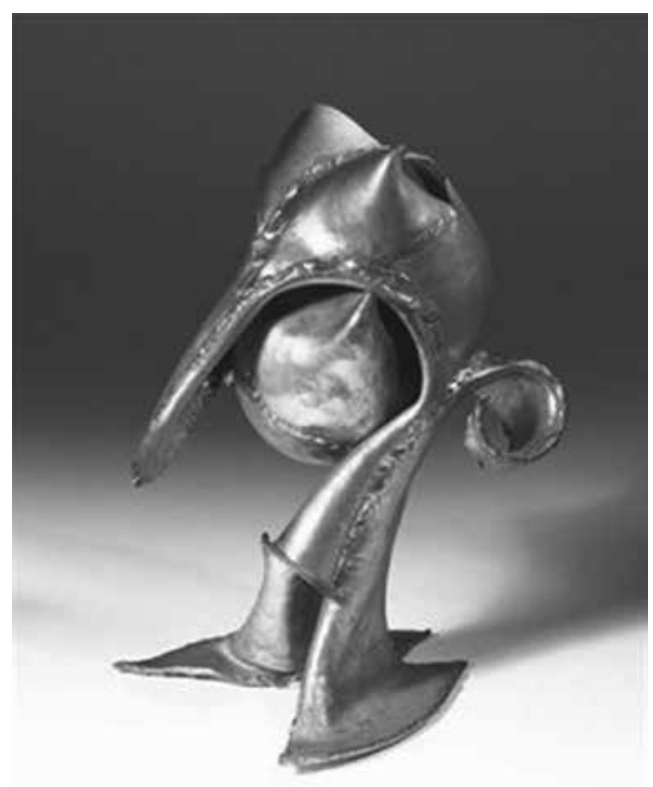

Fuente: http://www.christies.com 
Figura 11. Mannequin d'Oscar Domínguez. Denise Bellon (1938).

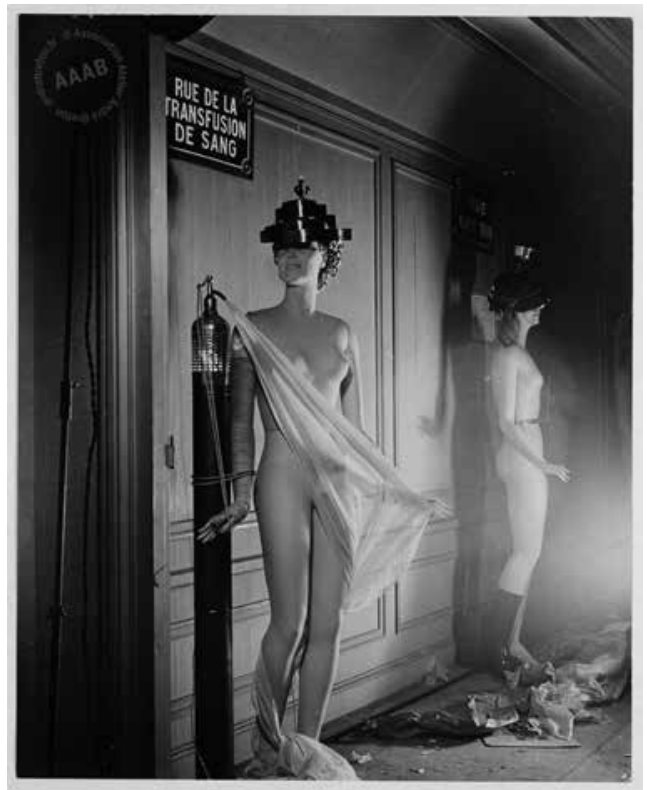

Fuente: http://www.andrebreton.fr

romano: Gradiva Rediviva, la mujer que daría nombre a la galería en la rue de Seine, descrita por Éluard como tienda de objetos (Aktypi, 2014). Logificar las cosas es inhumarlas: no pueden ser juzgadas como naturalezas muertas. Como ve Cortázar (2010), hay la oportunidad de tratarlas, de un "dialogo de las formas" (p. 165, planta alta). Hablan, se expresan como lo pernotó ante las estatuas broncíneas de Reinhoud. Estas "criaturas [dice] [...] ellas saben que el pitón finge no estar y el pitón sabe que ellas fingen que no lo saben" (figura 10). Esto quiere decir que simulan ausencia: formas petrificadas y emplazadas de un mundo cartesiano. No es gratuito que Cortázar haya escuchado ante la primera y última de ellas: "no crean una sola palabra de lo que dicen" (p. 166).

En Rayuela, Oliviera escucha los objetos; siente que palpitan; los halla dotados de una fuerza ignota, vivificados por una clase de poder. En verdad se empeña en contactar con su centro vital (Picon, 1975). Y al tocarlos no solo los ha liberado: les infunde su propio deseo de redimirse. Piensa: "mi único diálogo verdadero es con este jarrito verde" (Cortázar, 2003, p. 214). Oliveira "estudiaba el comportamiento extraordinario del mate, la respiración de la yerba [...] Hacía rato que le importaban las cosas sin importancia" (p. 214). Como sentía Breton, la existencia del objeto supone haber logrado rescatarlo del significado prefabricado. Una vez se les comunica sensibilidad sus gestos brotan. Al respecto, considera Picon (1975) que es el reloj-alcachofa de un cronopio sus hojas son horas comestibles y una vez agotadas se come con aceite, vinagre y sal (Cortázar, 2005)—, uno de los más originales objetos surrealistas creados por Cortázar.

No es difícil ver a Oliveira en silencio ante el jarro de mate; verlo dejar caer con tristeza el paraguas sobre la hierba. Al palpar el jarro sabe que su magia existe fuera de toda consciencia, fuera del ojo lacerado por el tedio: el ojo mecánico anclado a la ceguera de la realidad. Augural era para Breton y Cortázar que el mundo que nos rodea solo se transfigura con el ojo de la imaginación: el ojo del mundo invisible. Importante es aquí concluir que ambos dispusieron todo a la óptica de este ojo. Porque cada objeto nos detiene en su umbral: ¿cómo pasar al otro lado bajo una mirada que se yergue estática porque subordinada ante lo que, por cortedad de mira, se llama realidad?

Dice Breton (1988) en el Manifeste: "Tanto va la fe a la vida, a lo que en la vida hay de más precario - me refiero a la vida real-, que finalmente esa fe se pierde" (p. 311). Al 
otro lado de lo real impugnable, sin coartada en tanto sofístico por racionalista, fuera de la pseudorealidad de la "Gran costumbre" (Cortázar, 2003, p. 546) está la imaginación. Es en ella donde las cosas perviven porque es posible mirar el mundo por primera vez. Se trata de una resistencia ajena a toda defección; de inhumar una herencia secular agolpada en la cabeza. Medita Cortázar (2005): “Apretar una cucharita entre los dedos y sentir su latido de metal, su advertencia sospechosa. Cómo duele negar una cucharita, negar una puerta, negar todo lo que el hábito lame hasta darle suavidad satisfactoria. Tanto más simple aceptar la fácil solicitud de la cuchara, emplearla para revolver el café" (pp. 11-12).

El mundo de los objetos de la mano de la imaginación es ilimitado. ¿Qué tanto de la vida puede alcanzar la voluntad que ronda la magia de las cosas? Breton y Cortázar optaron por el niño que ingresa al cuarto con los ojos vendados para abrir la piñata de objetos quiméricos suspendida en la noche. La entrada de la juguetería está abierta: basta con cerrar los ojos. Pertinente es evocar uno de los juegos surrealistas: 1. los surrealistas entran en una habitación oscura; llevan objetos inventados, los más extraños al ojo humano; 2. un surrealista que los desconoce ingresa y siempre a oscuras irá instintivamente hacia un objeto elegible; 3. los otros, siguiendo el tacto, describen el objeto elegido, sus formas detalladas; 4 . a partir de las descripciones a ciegas un nuevo objeto será montado y fotografiado. El fotógrafo lo hará sin verlo; 5 . antes, el objeto habrá caído sobre un montículo de heno, en el campo visual de la cámara (la caída refuerza el efecto circunstancial, su particularidad por su ubicación y posición; 6. el objeto original y el reconstruido fotografiado son destruidos; 7 . la fotografía se guarda sin ser vista en una caja de metal hueco; 8. por último, el cubo que guarda la foto se sumerge en una masa de hierro fundido que al solidificarse la englobará. "Este pedazo informe de hierro fundido, de peso y volumen mediano, será el objeto psico-atmosférico-anamórfico" (Dalí, 1977, pp. 75, 76). Esta era la cristalización del objeto de la imaginación.

¿Cuál era el objeto precedente al creado? ¿Cómo era? ¿De dónde provenía? ¿Y el objeto derivado de aquél? Al terminar este proceso ¿qué insinuaba la forma de hierro fundido de su anterior existencia? Como recuerda Emmanuel Guigon (1997), “el objeto (el objectum del latín escolástico) es una 'cosa que está situada delante', 'que afecta al sentido"” (s. p.). En rigor, "el objeto es una realidad que se resiste". Expuesto al ojo humano presenta una presencia de criptograma. El sentido de su secreto consiste en que, en cuanto está situado delante, debe ser captado; el hecho de que se esconda es una señal a favor de la aventura humana. Desaparecida la distancia sujeto-objeto, este no es ya el ob-jeto en sentido común, es decir, lo que "cae (jecta) bajo el sentido de quien los hace o utiliza" (Guigon, 1997, s. p.). Redimido de su existencia utilitaria el objeto alcanzó una vida orgánica: liberaba su virtualidad por sus virtudes. Como testigo del mundo, el objeto es el mediador entre este y el ser humano. Es, como comunicase Dalí (1977), esa forma de hierro fundido en su insondable oscuridad.

Y el ojo humano permanecerá encendido y fijo en ese pedazo de hierro informe e inexpresivo de la misma manera que el misterio que consiste 
Figura 12. Les Gants. Man Ray (1933). Guante dejado por Lise Deharme en el Bureau de Recherches Surréalistes y citado por Breton en Nadja.

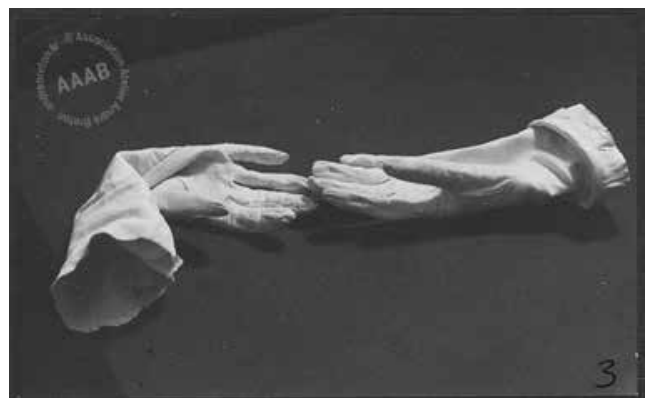

Fuente: http://www.andrebreton.fr

Figura 13. Beau comme la rencontre fortuite sur une table de dissection d'une machine à coudre et d'un parapluie. Man Ray (1933).

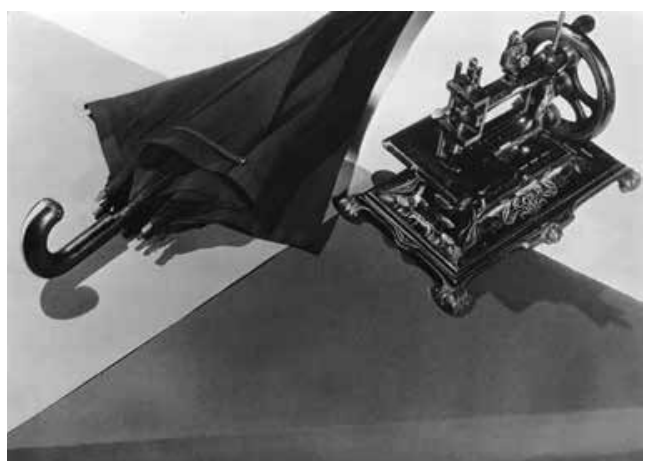

Fuente: http://www.manraytrust.com

Figura 14. Café aux petits garçons. Émile Van Moerkerken (1936).

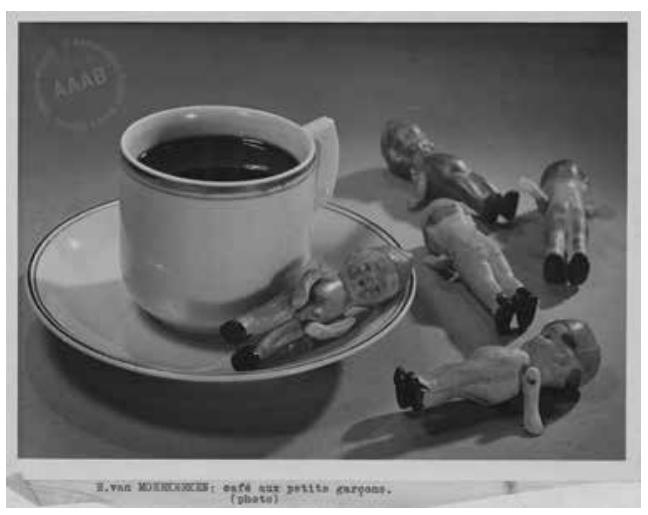

Fuente: http://www.andrebreton.fr habitualmente para el hombre en sumergirse en la contemplación soñadora del punto luminoso que es una estrella que brilla en el firmamento queda aniquilado en el mismo momento en que el contemplador se da cuenta de su ilusión... todo lo que puede ser visto del objeto concienzudamente envuelto en un paño antiguo y, además, sumergido en la oscuridad casi absoluta de la noche (pp. 76, 77).

Caro era para Breton y Cortázar el encuentro contingente con un objeto: era un choque de inusitado asombro. Si admiraban "el encuentro fortuito de una máquina de coser y un paraguas en una mesa de disección" (Lautréamont, 2005, p. 295) —clave para el objeto en el siglo $\mathrm{XX}$ - era porque a partir de este los más insólitos los concertaban ellos. Se trata de una frase emblemática en su historia (Hoyos, 2010). Este encuentro es el de dos realidades imprevistas y por ello fue una colisión poética (figuras $12 \mathrm{y}$ 13). Su desconcierto dio lugar a la exploración y aplicación del encuentro de objetos en el collage, el cadavre exquis, la pintura y el poème-objet en el que junto a las palabras aparecía uno de ellos destinado a producir un efecto con su irrupción incoherente. Ya el terrón de azúcar de Oliveira, la hoja de plátano o el retal rojo de Lucía, un alfiler, un botón, un hilo (como se presenta a Oliveira junto a las palanganas y relemanes en su celda de asilo) abrían una ventana para transfigurar la realidad.

Había un gran aprecio por los objetos en Breton y Cortázar. Les otorgaban la confidencia de saberlos compañeros presentes. Como señalaba Cortázar, el diálogo estaba abierto. Cada objeto, por banal que fuese, 
conservaba su arcanidad, ofrecía un acertijo, entramaba una emisión. Partimos de la postración de Oliveira: la consunción gradual de la imaginación en una realidad que justificando el ritmo de vida actual (llámese trabajo, madurez, adultez, responsabilidad) anula el vínculo con las cosas. Con este enrolamiento solo se ha rezagado su mundo. Por ello recordaba Cortázar (2006) la delación de Rilke: “y esto se llama perro, esto se llama casa [...] Ustedes están matando las cosas" (p. 539) (figura 14).

El propósito del movimiento fundado por Breton respecto al objeto fue crucial como vía alterna: oxigenó una existencia arrancada del mito por los excesos cerebrales. La conmoción de Bataille (2005) ante este orden cefálico es clara: “la vida humana está

Figura 15. Mains gantées. Philippe Migeat (2013), objeto surrealista de Valentine Hugo.

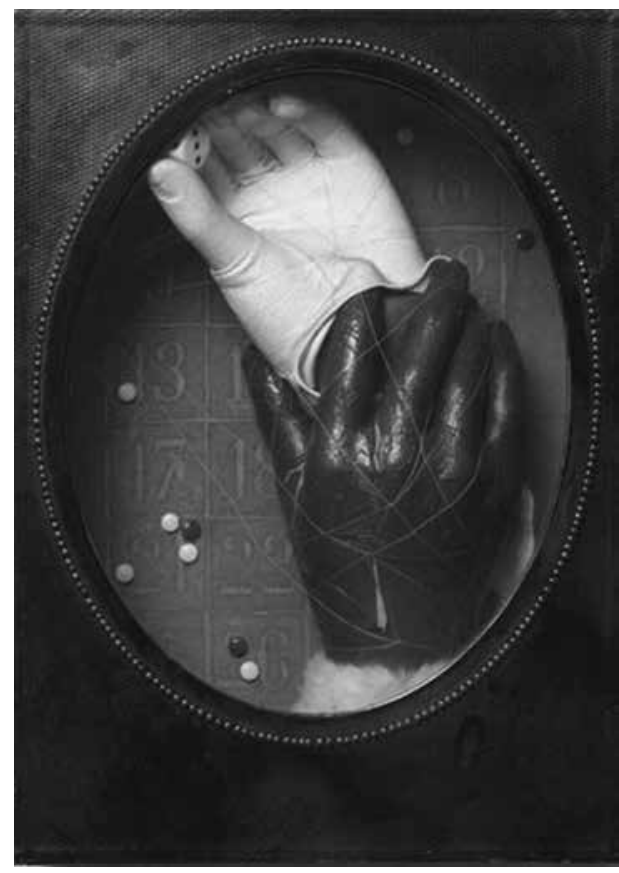

Fuente: http://www.centrepompidou.fr excedida por servir de cabeza y de razón al universo" (p. 22). El drama de Breton y sus compañeros lo vivió Cortázar. Es significativo, en este sentido, acercarse al puente de vasos comunicantes entre ambos: puente para acercarse a la vie des objets; que otorga una llave al diálogo Nadja-Rayuela y, ante todo, al diálogo fundamental que existe entre ellos.

En sus últimos años se veía a André Breton atrapando mariposas junto a su amigo de toda la vida, Benjamin Péret; buscando, a la orilla del mar, el "lenguaje misterioso de las piedras" (Breton, 1989, p. 137): la piedra-pájaro, la piedra cabeza de lechuza6. Quizá la búsqueda de las cosas es la insinuación alarmante de una invitación de carácter vital. Lo que ha sentido y descubierto Horacio Oliveira en el silencio y aislamiento de las cosas es la exhortación de un plazo perentorio que puede salvarlo: es un mensaje de higiene mental. Entonces, si se ha aceptado la invitación, tal vez en un día de lluvia, al atardecer, se sienta la necesidad de enterrar un paraguas como lo hizo Cortázar, recuerda Edith Aron, la Maga, evocando la tarde en que acompañaba al cronopio argentino en su errancia por las calles de París (Lladó, 2013).

\section{REFERENCIAS}

Adorno, T. W. (1986). Teoría estética. Madrid: Taurus.

Aktypi, M. (2013). Le surréalisme et l'objet. Centre Pompidou. Recuperado el 28 agosto de 2014, de http://mediation.centrepompidou.fr

6 La dispersión del estudio de Breton recaudó 46,02 millones de euros. En 1994 Le Centre Pompidou filmó el santuario en que lo había convertido: L'œil à l'état sauvage-L'atelier d'André Breton. 
Balakian, A. (1971). André Breton mago del surrealismo. Caracas: Monte Ávila.

Bataille, G., Caillois, R., Klossowski, P., Masson, A., Monnerot, J., Rollin, J, y

Wahl, J. (2005). Acéphale. (2da edición). Buenos Aires: Caja Negra.

Bellon, D. (1938). Mannequin d'Oscar Domínguez. Exposition internationale du Surréalisme. Association Atelier André Breton. Recuperado el 12 de febrero de 2015, de http://www.andrebreton.fr

Bellon, D. (1938). Phonographe de Domínguez: Jamais. Exposition internationale $d u$ Surréalisme. Recuperado el 26 de agosto de 2014, de http://binocheetgiquello.com

Bellon, D. (1938). Le taxi pluvieux de Salvador Dalí. Exposition internationale du Surréalisme. Association Atelier André Breton. Recuperado el 12 de febrero de 2015, de http://www.andrebreton.fr.

Bradu, F. (2012). André Breton en México. México, D. F.: Fondo de Cultura Económica.

Breton, A. (1931). Objet à fonctionnement symbolique. Centre Pompidou. Recuperado el 12 de febrero de 2015, de http:// www.centrepompidou.fr.

Breton, A. (1974). Apuntar del día. Caracas: Monte Ávila.

Breton, A. (1988). CEuvres complètes I. Paris: Éditions Gallimard.

Breton, A. (1989). Magia cotidiana. Madrid: Fundamentos.

Breton, A. (1999). CEuvres complètes II. Paris: Éditions Gallimard.

Breton, A. y Paul, É. (2003). Diccionario abreviado del surrealismo. Madrid: Siruela

Carsten, P. y Ingo F. (1992). Picasso. Colonia: Taschen.

Cortázar, J. (2003). Rayuela (16va. edición). Madrid: Cátedra.
Cortázar, J. (2005). Historias de cronopios y famas. Bogotá: Punto de Lectura.

Cortázar, J. (2006). Obra crítica. Barcelona: Círculo de Lectores.

Cortázar, J. (2010). Último round. México D.F.: RM Verlag.

Dalí, S. (1977). ¡SI!. Barcelona: Ariel.

D'Haese, R. (s. f.). Figura. Christie's. Recuperado el 26 de agosto de 2014, de http:// www.christies.com

Giacometti, A. (1930). Boule suspendue. Fondation Giacometti. Recuperado El 26 de agosto de 2014, de http://www.fondation-giacometti.fr

Guigon, E. (1997). El objeto surrealista. Recuperado el 25 de agosto de 2014, de http://personales.upv.es/fmarti/eii/objsurr.htm

Hoyos, C. (2010). La imagen literaria de París. Desde Mercier, Baudelaire y el Surrealismo hasta Rayuela de Julio Cortázar (Tesis doctoral). Universitat Pompeu Fabra, Madrid, España.

Heidegger, M. (1995). Caminos de bosque. Madrid: Alianza.

Lautréamont, C. de. (2005). Los cantos de Maldoror. Madrid: Cátedra.

Lottman, H. R. (2003). El París de Man Ray. Barcelona: Tusquets.

Lladó, A. (27 de junio, 2013). Cortázar me dijo: 'voy a hacer un libro mágico'. Revista de Cultura. Recuperado el 20 de julio de 2014, de http://www.revistaenie.clarin.com/literatura/Entrevista-Edith-Aron-Cortazar-Rayuela-un-libro-magico_0_945505778.html

Méndez LLopis, C. (2010). La imagen surrealista. e.nnova, (2), 9-33. Recuperado el 2 de septiembre de 2014, de http:// www2.uacj.mx/publicaciones/e-nnova2.pdf 
Polizzotti, M. (2009). Revolución de la mente: la vida de André Breton. México, D. F.: Fondo de Cultura Económica.

Picon Garfield, E. (1975). ¿Es Julio Cortázar un surrealista? Madrid: Gredos.

Picon Garfield, E. (1990). Cartas a una pelirroja. Madrid: Orígenes.

Puelles Romero, L. (2005). El desorden necesario. Filosofía del objeto surrealista. Murcia: Cendeac.

Ray, M. (1933). Vue de l'Exposition du surréalisme à la galerie Pierre Colle. Galerie Pierre Colle. Association Atelier André Breton. Recuperado el 26 de agosto de 2014, de http://www.andrebreton.fr

Ray, M. (1933). Les Gants. Association Atelier André Breton. Recuperado el 26 de agosto de 2014, de http://www.andrebreton.fr

Ray, M. (1933). Beau comme la rencontre fortuite sur une table de dissection d'une machine à coudre et d'un parapluie. Man Ray Trust. Recuperado el 12 de febrero de 2015, de http://www.manraytrust.com.
Ray, M. (1934). Giacometti, L'objet Invisible. Acquisition Musée national d'art moderne. Centre Pompidou. Recuperado el 26 de agosto de 2014, de http://www. centrepompidou.fr

Ray, M. (1937). De la hauteur d'un petit soulier faisant corps avec elle. Association Atelier André Breton. Recuperado el 26 de agosto de 2014, de http://www. andrebreton.fr

Picasso, P. (1951). La guenon et son petit. Musée National Picasso-París. Recuperado el 12 de febrero de 2015, de http:// www.museepicassoparis.fr

Ubac, R. (1935). Pierres. Objets naturelles en Lesina. Exposition Internationale du Surréalisme. Association Atelier André Breton. Recuperado el 12 de febrero 2015, de http:// www.andrebreton.fr

Van Moerkerken, É. (1936). Café aux petits garçons. Association Atelier André Breton. Recuperado el 12 de febrero de 2015, de http://www.andrebreton.fr 